10

\title{
"Fostering" Effective Foster Parent Training Programs : Parent-Child Interaction Therapy Adaptations for the Child Welfare Setting
}

\author{
Robin C. Han ${ }^{1, *}$, Christopher K. Owen ${ }^{1}$, Corey C. Lieneman ${ }^{1}$ and Cheryl B. McNeil ${ }^{1}$ \\ ${ }^{1}$ Department of Psychology, West Virginia University, Morgantown, WV 26506, United States
}

\begin{abstract}
Foster parents face considerable challenges in caring for children in the child welfare system, many of whom have significant behavioral difficulties [1]. Foster parents often lack the training and support needed to manage these externalizing behaviors, which contribute to parenting stress and are highly predictive of placement breakdowns [2,3]. Although child welfare agencies provide foster parents with pre-service training experiences, they often lack the capacity and financial resources to implement gold standard, evidence-based interventions that address child behavior difficulties. Parent-Child Interaction Therapy (PCIT) has been well-established as an empirically supported treatment for disruptive behavior, yet standard delivery of PCIT to children in the foster care system is often impractical due to time, financial, childcare, and personnel constraints. Adaptations of PCIT for the foster care setting may remove some of these barriers to treatment. These adaptations have typically retained the parent-coaching principles inherent to PCIT but replaced the traditional 12 - to 20 -week format with a shorter, less intensive treatment regimen in order to maintain feasibility within the child welfare context. Preliminary findings from studies using abbreviated formats of PCIT suggest effectiveness of such adaptations in reducing externalizing behavior in foster children and maintaining behavioral improvements several months after the end of the treatment.
\end{abstract}

Keywords: Foster parent training, Foster children, PCIT, Child welfare, Externalizing behavior, Child behavior difficulties.

\begin{tabular}{|l|l|l|l|}
\hline Article History & Received: November 08, 2019 & Revised: January 31, 2020 & Accepted: February 03, 2020 \\
\hline
\end{tabular}

\section{INTRODUCTION}

The role of foster parents in the child welfare system is multi-faceted; foster parents are responsible for meeting the physical, social-emotional, educational, and medical needs of the children in their care. These children often have histories of maltreatment or neglect that put them at risk for developing externalizing symptoms and, in many cases, psychological disorders [1 - 4]. Data from a national survey of 2,813 foster children under the age of 6 indicated conduct problems to be the most common areas of difficulty, more so than cognitive, communication, social, or adaptive difficulties [1]. Previous studies have shown that disruptive behavior is associated with adverse outcomes for foster children, including greater placement instability [2, 3] and lower rates of reunification with biological parents [5]. Many foster parents feel illequipped to handle severe conduct problems, which ultimately contribute to parenting stress and caregiver burden [6]. In fact, foster parents have identified the management of challenging behavior as one of their greatest training needs [7] and cited the inability to handle a foster child's behavior as a major consideration for ending a placement [8]. Thus, foster parents

\footnotetext{
* Address correspondence to this author at Department of Psychology, West Virginia University, 53 Campus Drive, Morgantown, WV 26506, United States; E-mail:rc0115@mix.wvu.edu,
}

require training in the effective management of maladaptive child behavior. By providing parenting interventions that address child behavior difficulties, child welfare systems can set foster parents up for greater success, thereby increasing placement stability and foster parent retention [9].

\section{BEHAVIOR PROBLEMS IN FOSTER CHILDREN}

\subsection{Prevalence}

Approximately half of all children entering the foster care system exhibit clinically significant behavioral or emotional problems and are in need of mental health services [10]. One of the first studies assessing the mental health of children in the foster care system was published by McIntyre and Kessler [11] who sampled 158 children in foster care between 4 and 8 years of age. Results from this study demonstrated that children in foster care exhibited a much higher rate of mental health concerns than those in the general population [11]. Similarly, Clausen, Landsverk, Ganger, Chadwick, and Litrownik [12] found that nearly two out of five foster children scored above the clinical cut-off point on the Total Problems scale on the Child Behavior Checklist (CBCL) [13]. In this study, Clausen et al. [12] compared the rates of mental health problems in children between the ages of 4 and 16 years in foster care across 3 counties in California. The findings from this study 
align with the previous findings demonstrated in Tennessee [11], wherein 43 to $50 \%$ of foster children displayed clinically significant behavior problems on CBCL narrow-band subscales (e.g., attention problems, aggressive behavior), broad-band scales (i.e., internalizing and externalizing), or Total Problems scale [12].

Heflinger, Simpkins, and Combs-Orme [14] examined externalizing behaviors among foster children and analyzed data from 105 children (ages 2-18) in state custody through the Children's Problem Outcome Review Team. Heflinger et al. [14] utilized the CBCL to provide information about problems at a global level (i.e., Total Problems score), as well as two broad-bands of behavior: Internalizing Problems and Externalizing Problems [13]. At the global level, 33\% of children in foster care reported having significant behavior problems; moreover, $31 \%$ of foster children demonstrated externalizing problems at either borderline or clinical levels [14]. Specifically, $20 \%$ were reported to have externalizing problems within the clinical range of severity, which is similar to children already receiving treatment in clinical settings [14].

\subsection{Maltreatment}

According to Clausen et al. [12] there are two reasons children in foster care are at higher risk for mental health problems: (1) child maltreatment and (2) adjustment difficulties inherent in foster care. Maltreatment negatively impacts children across multiple domains, such as increased disruptive behavior problems, social withdrawal, and difficulty developing secure attachments [15 - 17]. Externalizing behavior problems often present as core symptoms in maltreated children; that is, externalizing behavior (e.g., oppositionality) is highly correlated with childhood physical abuse [18]. Maltreated children in foster care may benefit most from an intervention that aims to decrease externalizing behavior, provide foster caregivers with safe discipline strategies, and enhance the foster caregiver-child relationship.

\subsection{Placement Stability}

Behavior problems in foster children are associated with placement instability [19]. In a study examining the placement experiences of 184 foster children, Palmer [20] demonstrated that children's problem behavior was a stronger predictor of placement stability than the child's gender, parents' preparation of the child for separation, or social workers' training in separation. Newton, Litrownik, and Landsverk [21] conducted a prospective study examining the relationship between change in placement and problem behavior in foster children. Results from this study were consistent with Palmer's [20] earlier findings: externalizing behavior at entry into foster care was found to be the strongest predictor of placement changes [21]. This finding reinforces the notion that children entering the foster care system with high rates of externalizing behavior are less likely to have successful, stable placements.

Highlighting the need for foster children to find a permanent placement, Newton et al. [21] found that multiple placement disruptions can aggravate children's mental health. For foster children who were initially within normal limits on the $\mathrm{CBCL}$, the number of placement breakdowns predicted increased internalizing and externalizing behaviors. While
Palmer [20] asserted that foster care workers are already making strong efforts to help children modify their behavior, foster children may benefit from caregiver-child focused interventions aimed at reducing disruptive behavior and strengthening the caregiver-child bond.

\section{FOSTER PARENT TRAINING PROGRAMS}

Although foster parents receive mandatory pre-service training, the content of these programs varies widely by state and often does not include training in parenting skills that specifically target negative child behavior [22]. Two of the most commonly used pre-service training curricula are Model Approach to Partnerships in Parenting Group Preparation and Selection of Foster and/or Adoptive Families (MAPP/GPS) and Foster Parent Resources for Information, Development, and Education (PRIDE). Both models seek to orient potential foster parents to their roles and responsibilities as foster parents and members of the child welfare team; however, neither program focuses on teaching specialized skills to address challenging child behavior or traumatic stress [22]. Despite their widespread adoption by numerous child welfare agencies across the country, the MAPP and PRIDE programs lack empirical study and support [23]. There is emerging evidence that the PRIDE program can increase parent knowledge of the program curriculum [24] and maintain these gains 18 months after the end of the program [25], but there is no evidence that the program improves behavioral outcomes for foster children. Evaluations of the MAPP/GPS program found that the program did not sufficiently prepare foster parents for their roles [26] nor did it prepare them to address behavior challenges in foster children [27].

Several meta-analyses and literature reviews on parenting interventions in foster care have been conducted in recent years and have demonstrated positive parent and child outcomes [9, 28 - 32]. Training programs used in the foster care setting are diverse in theoretical framework (e.g., behavioral, attachmentbased, cognitive-behavioral, psychodynamic) and service delivery methods (e.g., group training, wraparound services, phone consultations, home/clinic-based) [28]. Uretsky and Hoffman [31] reviewed 11 studies on group-based foster parent training that evaluated 1 of 4 models: Incredible Years (IY), Keeping Foster and Kin Parents Supported and Trained (KEEP), Middle School Success program, and CognitiveBehavioral Parent Training (CBPT). Two of these interventions (IY and KEEP) were adaptations of existing and wellestablished parenting interventions. The meta-analysis showed significant decreases in child problem behavior across all studies, with treatment effects maintained for studies that included three or more time points [31]. Several of the studies reviewed also indicated decreases in parental depression and stress and increases in parenting skills. Solomon et al. [30] included 16 studies in their meta-analysis evaluating the efficacy of foster parent training in reducing child behavior problems. A number of different interventions were included in this meta-analysis: KEEP, adaptations of IY, Attachment and Behavioral Catch-Up (ABC), CBPT, and the Love and Logic Program, among others. Solomon and colleagues [30] found that foster parents in the treatment groups reported fewer child behavior problems (i.e., small, but significant mean effect size) 
and greater parenting skills and knowledge (moderate, significant mean effect size) than those in the control groups. This meta-analysis highlighted the importance of integrating empirically supported treatments for maladaptive child behavior into foster parent training. Schoemaker et al. [29] conducted a series of eight meta-analyses and found significant improvements in child behavior problems, as well as parental sensitivity, dysfunctional discipline, parenting knowledge, and parenting stress. However, no significant changes were observed in placement stability, children's cortisol levels, or attachment security following the intervention [29]. Certain elements of foster parent training programs seem to be essential to improving outcomes for both child and caregiver. A meta-analysis [32] highlighted the importance of enhancing the foster child-foster parent relationship, improving attachment quality for young children, and targeting behavior problems and symptoms of stress. In a review of foster parent training programs, Rork and McNeil [9] recommended the use of empirically supported treatments, especially those that are behaviorally based, to guide interventions for foster parents.

\section{PARENT-CHILD INTERACTION THERAPY}

One parent training program that encompasses these key components (e.g., behaviorally based, targets externalizing behaviors, enhances the parent-child relationship) is ParentChild Interaction Therapy (PCIT). PCIT is an evidence-based, manualized treatment for behavioral symptoms in children between the ages of two and seven years [33]. This behavioral parent-training program was first designed to treat disruptive behavior disorders through weekly, one-hour sessions involving the child and his or her caregivers [34]. Today, PCIT is indicated in treating symptoms of childhood anxiety [35], depression [36], Attention-Deficit/Hyperactivity Disorder (ADHD) [37], Autism Spectrum Disorder (ASD) [38], maltreatment [39], and other behavioral health concerns. PCIT is unique in that it involves live therapist coaching of the caregiver through an earpiece and two-way mirror, incorporates weekly behavioral assessment measures, and depends upon skill-based mastery criteria for progression through treatment.

\subsection{PCIT Basics}

PCIT is made up of two treatment phases [40]. In the first phase, Child-Directed Interaction (CDI), a therapist spends one session, teaching caregiver(s) foundational play therapy skills. The caregiver is taught to use "PRIDE" skills—praise, reflect, imitate, describe, enjoy_during one-on-one "special playtime" with the child during weekly therapy sessions and daily, 5minute practice sessions in the home. Caregivers also learn to avoid questions, commands, and negative talk, also known as the "don't" skills, during CDI. Using a microphone and earpiece, a PCIT therapist provides live coaching to caregivers from behind a two-way mirror as caregivers engage in play with their child. Coaching involves a parallel process wherein therapists employ the same behavioral principles (e.g., praising appropriate use of skills, avoiding negative talk) to improve caregivers' skills as caregivers are expected to use with their children. CDI coaching sessions continue until caregiver skills meet mastery criteria (i.e., 10 praises, 10 reflections, 10 descriptions, and 3 or fewer "don't skills" during a 5-minute coding period). The use of mastery criteria is intended to capitalize on the idea of overlearning skills; caregivers who demonstrate high ratios of positive to negative parenting skills are more likely to retain these habits outside of sessions [33]. CDI mastery typically occurs after about six to eight sessions of PCIT.

Following CDI mastery, the therapist teaches caregiver(s) a set of disciplinary strategies focused on compliance training. This second phase of treatment, Parent-Directed Interaction (PDI), aims to hone caregiver skills in giving effective commands (i.e., commands that are singular, specific, direct, and positively stated) and delivering consistent, predictable consequences (i.e., labeled praise for compliance and time-out from positive reinforcement for noncompliance). Again, caregivers are coached in PDI skills during therapy sessions and complete daily at-home practice of both CDI and PDI skills. Mastery of the PDI phase occurs when the caregiver gives $75 \%$ or greater effective commands and $75 \%$ or greater correct subsequent follow-through, during a 5-minute coding session. Caregivers often achieve PDI mastery in six to ten sessions.

Following mastery of CDI and PDI, PCIT therapists work ideographically with families to achieve a variety of remaining goals such as decreasing sibling conflict, improving public behavior, and generalizing behavioral gains to the classroom. Throughout PCIT, caregivers also complete a weekly selfreport measure of child behavior problems called the Eyberg Child Behavior Inventory (ECBI) [41]. In addition to CDI and PDI skills mastery, families must report child behavior problems within normal limits on the ECBI and confidence in managing their child's behavior in order to graduate from PCIT [33]. The typical course of PCIT lasts for about twelve to twenty sessions from baseline assessment to graduation.

\subsection{Empirical Support for PCIT}

For more than four decades, researchers have investigated the impact of PCIT through efficacy and effectiveness trials in a variety of contexts. See Lieneman, Brabson, Highlander, Wallace, and McNeil [42] for a recent comprehensive literature review. Effect sizes for pre- to post-treatment decreases in child behavior problems as reported on the ECBI are routinely measured in the "very large" to "huge" range in samples from community-based treatment settings (e.g., $d=2.30$ [43], $d=$ 1.65 [44]). See Cohen [45] and Sawilowsky [46] for more information on effect size classifications. Families report maintenance of treatment gains at one-, two-, three-, and sixyear follow-up assessments subsequent to PCIT [47 - 49]. Drawing from a meta-analysis of common effective components of behavioral parent training programs, PCIT's large effects can be attributed in part to its core features of: (1) increasing positive interactions, (2) in-session practice, (3) emotional communication, and (4) time-out of from positive reinforcement $[50,51]$. The positive effects of PCIT have been measured through caregiver-based outcomes as well. A 2007 meta-analysis of PCIT research demonstrated improvements across studies in positive and negative parenting practices following treatment [52]. Improvements in caregiver emotion regulation [53], as well as decreases in parenting stress [54 $56]$ and risk for future maltreatment $[39,57]$ are also evident. 


\subsection{Cross-cultural Validity}

A growing literature base provides evidence of PCIT's generalizability across diverse cultural groups [58]. PCIT has demonstrated positive treatment effects in samples of predominately African-American [59, 60], Latinx [61 - 63], and Native American [64] cultural groups. A variety of adaptations or tailoring approaches have been used to improve upon the cultural validity of PCIT; for example, some Puerto Rican families preferred the involvement of extended family members in the treatment [63]. Worldwide, evidence of PCIT's effectiveness has been reported by researchers in Australia [65], Norway [66], China [67], Germany [68], Iran [69], Japan [70], South Korea [71], Taiwan [72], the Netherlands [73], and the United States [74].

\section{PCIT IN THE CHILD WELFARE CONTEXT}

Several studies have examined the effectiveness of PCIT for foster child-foster parent dyads [75, 76]. A case study on a foster mother and her four-year-old foster son demonstrated significant reductions in parenting stress and child behavior problems that were no longer in the clinical range on the ECBI and CBCL [75]. Observational data from the Dyadic ParentChild Interaction Coding System (DPICS) [77] showed an increase in the foster mother's use of praise and behavioral descriptions and a decrease in questions and commands. Fricker-Elhai, Ruggiero, and Smith [78] conducted a clinical case study of PCIT with two biological siblings with significant maltreatment histories and their foster parents. PCIT was effective in bringing the ECBI Problem and Intensity scores below clinical range for both children and to normal limits on the Teacher Rating Form (TRF) [13] completed by the children's teachers, except for an elevated Aggressive Behavior score for one sibling. In a study comparing nonabusive biological parent-child dyads to foster parent-foster child dyads, Timmer and colleagues [76] found that PCIT yielded strong treatment effects on child problem behavior and caregiver distress, but no major differences were found between the two parent groups.

\subsection{Feasibility}

Despite the overwhelming evidence that PCIT is effective in improving behavioral outcomes for children with challenging behavior or histories of maltreatment, the reality is that PCIT may not be feasible in some child welfare contexts due to a number of logistical and financial restraints. PCIT may be cost-prohibitive for some child welfare agencies, with startup costs estimated at $\$ 14,000$ and treatment costs estimated at $\$ 1,000$ per client [79]. PCIT also requires delivery by trained mental health providers with masters' degrees, which for many agencies may require training of staff and restructuring of personnel [80]. High attrition rates pose another problem for child welfare agencies looking to use PCIT as a model for preservice training. Standard PCIT has an estimated 33\% dropout rate [81], and non-kin foster parents have higher attrition rates than kinship foster parents [82]. Mersky and colleagues [83] cited the intensity and duration of treatment as a major barrier to the implementation of PCIT in the foster care setting. Foster parents typically have multiple children in their care and may be less inclined to participate in an intensive 12 - to 20 -week program focused on a single child. The recognition of these barriers to the treatment has served as a catalyst for the development of PCIT adaptations for the child welfare system.

\section{PCIT ADAPTATIONS FOR FOSTER PARENTS}

\subsection{PCIT with in-home Coaching}

One such adaptation maintained all the components of standard PCIT but added one hour per week of in-home coaching [84]. The rationale for the additional in-home coaching practice was to promote the generalizability of skills and allow the caregiver to practice skills with therapist support in a real-world setting, complete with siblings, other adults, and environmental distractions. Although the study did not focus on foster parents, non-kin foster parents were included in the sample, along with biological parents and kin caregivers. Participants were randomly assigned to either receive additional in-home PCIT coaching or in-home social support services. Both PCIT with and without in-home coaching yielded similar improvements in child and caregiver behavior; caregivers who received additional in-home coaching sessions did not fare better in terms of skill acquisition, quality of performance by the last session, or speed in completing treatment than those in the social support group. However, those in the in-home coaching group used significantly more positive verbalizations, had lower parental stress, and experienced child behavior as less problematic (as measured by the ECBI Problem Scale).

\subsection{Two-day PCIT Workshop}

McNeil, Herschell, Gurwitch, and Clemens-Mower [85] conducted an exploratory single-group study on a condensed version of PCIT with 30 foster child-foster parent dyads. Instead of the individualized, multi-week format, foster parents in this study attended a two-day group training. On the first day of training, foster parents attended a didactic session without their foster children in order to learn CDI skills and engage in discussions and role-plays to enhance skill acquisition. On the second day of training, foster parents brought their foster child with them and were trained in PDI skills. They were then given an opportunity to practice discipline skills with their children while a therapist coached from behind a one-way mirror. Other foster parents watched these parent-child interactions from the observation room, and childcare was provided any time a parent-child dyad was not being coached. The workshop ended with the development of a plan for each foster parent to roll out PCIT into the home setting.

In this study, the key components of PCIT were maintained (e.g., CDI and PDI skills, live caregiver coaching). However, a number of elements from the standard format were excluded in order to adapt PCIT to the child welfare context: at-home practice, coding of CDI and PDI skills, progress based on mastery, and the use of a back-up room in the time-out procedure (i.e., foster parents had the option of using a back-up room or another consequence such as restriction of privilege). This modified format of PCIT presented a number of advantages for the foster parent population. The two-day workshop significantly reduced the time commitment for caregivers and the cost of training for child welfare agencies, thereby increasing the feasibility of implementation. The group-based format lent itself to the discussion, observational 
learning, and social support among the foster parent participants.

After the 2-day workshop, 27 of the 30 participants completed a 1-month follow-up, and 8 participants completed a 5-month follow-up. Although the average pre-treatment ECBI Problem and Intensity Scale scores were measured in the clinical range, these scores fell in the average range one month after treatment. Interview data collected at the 1-month followup indicated that $80 \%$ of foster parents were using skills acquired during the workshop and $68 \%$ were satisfied with the time-out procedure. Scores on a treatment satisfaction survey were high immediately following the training but saw a small, yet statistically significant drop in satisfaction ratings at follow-up. Parents who completed the 5-month follow-up continued to report ECBI Intensity scores below clinical cutoffs and a decline in Problem scores, suggesting that these parents were better able to manage their children's behavior. The findings from this single-group study were promising in that they offered preliminary support for the use of a two-day workshop format for foster parents and their children. The methodological weaknesses of this study (e.g., lack of a control group, small sample size) prompted further evaluation of this abbreviated format.

\subsection{Project Connect}

Project Connect is a PCIT adaptation that was developed as an extension of the McNeil et al. [85] study in collaboration with two community partner agencies [86]. The group format was retained, but biweekly phone consultations and homework were added to support the transfer of skills to the home environment. Observational data using the DPICS-III [87] was also added to track changes in parenting behavior from baseline to eight weeks after baseline. The authors examined two variations of the model: (1) brief PCIT, a two-day workshop followed by six phone consultations conducted over eight weeks and (2) extended PCIT, a three-day workshop followed by four phone consultations conducted over six weeks $[80,86]$. Trainings were delivered by PCIT-trained therapists and took place on Saturdays for approximately eight hours with a group of six to eight families. Phone consultations were 15 to 20 minutes in length and typically occurred in the evenings. Additionally, childcare was provided for all Saturday sessions to remove barriers to participation, namely for foster parents with multiple children in their care.

The schedule of the first Saturday workshop began with didactic instruction on CDI skills, followed by role-playing to practice these skills. The therapists then coached the foster parents as they practiced CDI skills on one another. The bulk of the training was dedicated to live coaching; there were 3, 45minute live coaching sessions, and all parents received at least 2 coaching sessions. Foster parents not actively engaged in live coaching observed another parent's live coaching session from an observation room. The session ended with a discussion of questions and homework, and phone consultations were scheduled with each family. The second workshop followed the same format as the first but with PDI skills instead of CDI skills. For the three-day workshop, foster parents received an additional Saturday session at the eight-week mark. Phone consultations allowed providers to follow up with families on homework, answer any questions, and ensure foster parents were implementing PCIT skills in the home.

Families were randomly assigned to the two-day workshop condition, three-day workshop condition, or a waitlist control group. Rates of attrition were similar across the 3 groups (i.e., approximately $25 \%$ ), a relatively low rate of attrition compared to other PCIT studies $[56,81]$. The fact that the attrition rate did not differ between the brief and extended conditions indicated that the booster session did not negatively impact foster parent engagement [86]. Mersky and colleagues [80, 83] reported more detailed findings from this investigation. Foster parents in the two treatment conditions reported significant decreases in parenting stress on the Parenting Stress IndexShort Form (PSI-SF) [88] and improvements in parenting behavior [83]. Foster parents improved on measures of labeled praise, positive parenting behavior, and negative parenting behavior, but no differences between groups were found on the use of negative talk. There were no significant outcome differences between the brief PCIT and extended PCIT versions, which supports the use of the more time- and costeffective two-day model over the three-day model [83]. Both interventions yielded significant changes in child behavioral outcomes [80]. Scores on the ECBI Intensity and Problem Scales decreased for all 3 groups, and all groups had ECBI Problem scores below the clinical cutoff at 14 weeks after the baseline assessment. However, only the two treatment groups saw scores drop below the clinical cutoff on the ECBI Intensity Scale. Similarly, scores on the CBCL Externalizing and Internalizing Scales significantly decreased for all three groups, but only the two intervention groups had scores that fell below the clinical threshold post-treatment. Upon further analysis, Mersky et al. [80] found that those in the extended condition experienced further improvement in internalizing and externalizing behavior after the 8-week mark, but this was not the case for those in the brief condition. Although these results must be bolstered by further study, they suggest that a booster session may help with the maintenance of gains seen in foster parent and foster child behavior.

\subsection{Brief PCIT}

An exploratory study based on the abbreviated PCIT models for foster parents utilized a 5- to 7-session, clinicbased, individualized format [89]. Brief PCIT maintained more of the standard format of PCIT than the group-based formats, and thus provided foster parents with more opportunities for individualized coaching. The first session was a typical intake/observation session, followed by 2 sessions dedicated to CDI teaching and coaching. An optional CDI coach session was added if needed. Foster parents then received 2 sessions of PDI teaching and coaching with the option of a third PDI session if needed. Preliminary findings from a sample of six participants demonstrated a decrease in scores on both ECBI Intensity and Problem Scales for all but one participant. Two of the participants had clinically significantly pre-treatment scores on both ECBI scales that were no longer in the clinical range post-treatment. A qualitative study on Brief PCIT in the child welfare context identified additional barriers by asking foster parents and providers about their experiences with the intervention [90]. In this particular study, PCIT providers 
added elements to Brief PCIT in order to address child traumatic stress (e.g., psychoeducation for parents on trauma and traumatic stress and physiological/cognitive relaxation strategies). Overall, foster parents cited minimal challenges to participating in treatment but stated that the time commitment was difficult to manage. Foster parents deemed the therapeutic alliance with their PCIT provider to be a tremendous source of support that promoted success and retention. They also found the integration of trauma-informed treatment to be helpful in understanding their foster children's behavior and emotions. The practitioners, on the other hand, cited two main barriers to treatment: (1) foster parents' perceived stigma associated with participating in treatment and (2) foster parents' tendency to overreport child behavior difficulties. To problem-solve around these issues, practitioners formed small groups or "learning collaboratives" comprised of approximately seven therapists to discuss challenges, brainstorm possible solutions, and promote fidelity to the model. The work of Blair et al. [89, 90] has introduced yet another abbreviated adaptation of PCIT with its own modifications for both foster parents and their providers.

\section{CONCLUSION}

Preliminary studies on PCIT adaptations for foster parents have demonstrated improvements in child behavior problems, parental stress, and positive parenting behavior. There is empirical support for an abbreviated version of PCIT for the child welfare context and the addition of in-home coaching or follow-up phone consultations. The abbreviated models of PCIT reduce many of the barriers to treatment and make this adaptation a more feasible option for both foster parents and child welfare agencies. However, further study is needed to disaggregate the effects of these adaptations and determine which elements are most effective in reducing problem behavior, parental stress, and negative parenting behavior. Although there is some evidence that a booster session may be helpful in solidifying parental knowledge and use of skills, more research needs to be conducted on dosage effects with more follow-up assessments to determine if effects wear off over time. There is also evidence that some behavior (e.g., negative talk0 [83] may be harder to change with only a twoor three-day workshop and may require more intensive intervention to see significant improvement. Studying individual components of the adaptation (e.g., phone consultations, observational learning, group discussions, booster sessions) will be helpful in building a more robust parenting intervention that child welfare agencies can readily and widely adopt.

\section{CONSENT FOR PUBLICATION}

Not applicable.

\section{FUNDING}

None.

\section{CONFLICT OF INTEREST}

The authors declare no conflict of interest, financial or otherwise.

\section{ACKNOWLEDGEMENTS}

Declared None.

\section{REFERENCES}

[1] Stahmer AC, Leslie LK, Hurlburt M, et al. Developmental and behavioral needs and service use for young children in child welfare. Pediatrics 2005; 116(4): 891-900.

[http://dx.doi.org/10.1542/peds.2004-2135] [PMID: 16199698]

[2] Baum AC, Crase SJ, Crase KL. Influences on the decision to become or not become a foster parent. Fam Soc 2001; 82(2): 202-13. [http://dx.doi.org/10.1606/1044-3894.205]

[3] James S. Why do foster care placements disrupt? An investigation of reasons for placement change in foster care. Soc Serv Rev 2004; 78(4): 601-27.

[http://dx.doi.org/10.1086/424546]

[4] Oswald SH, Heil K, Goldbeck L. History of maltreatment and mental health problems in foster children: a review of the literature. J Pediatr Psychol 2010; 35(5): 462-72.

[http://dx.doi.org/10.1093/jpepsy/jsp114] [PMID: 20007747]

[5] Landsverk JA, Davis I, Ganger W, Newton RR, Johnson I. Impact of psychological functioning on reunification from out-of-home placement. Child Youth Serv Rev 1996; 18(45): 447-62. [http://dx.doi.org/10.1016/0190-7409(96)00014-X]

[6] McCarthy G, Janeway J, Geddes A. The impact of emotional and behavioural problems on the lives of children growing up in the care system. Adopt Foster 2003; 23(3): 14-9.

[http://dx.doi.org/10.1177/030857590302700305]

[7] Hebert CG, Kulkin H. An investigation of foster parent training needs. Child Fam Soc Work 2017; 23(3): 256-63.

[http://dx.doi.org/10.1111/cfs.12413]

[8] Brown JD, Bednar LM. Foster parent perceptions of placement breakdown. Child Youth Serv Rev 2006; 28: 497-1511

[http://dx.doi.org/10.1016/j.childyouth.2006.03.004]

[9] Rork KE, McNeil CB. Evaluation of foster parent training programs: A critical review. Child Fam Behav Ther 2011; 33(2): 139-70.

[http://dx.doi.org/10.1080/07317107.2011.571142]

[10] Burns BJ, Phillips SD, Wagner HR, et al. Mental health need and access to mental health services by youths involved with child welfare: a national survey. J Am Acad Child Adolesc Psychiatry 2004; 43(8): 960-70.

[http://dx.doi.org/10.1097/01.chi.0000127590.95585.65] [PMID: 15266190]

[11] McIntyre A, Keesler TY. Psychological disorders among foster children. J Clin Child Psychol 1986; 15(4): 297-303.

[http://dx.doi.org/10.1207/s15374424jccp1504_2]

[12] Clausen JM, Landsverk J, Ganger W, et al. Mental health problems of children in foster care. J Child Fam Stud 1998; 7(3): 283-96.

[http://dx.doi.org/10.1023/A:1022989411119]

[13] Achenbach TM. Integrative guide for the $1991 \mathrm{CBCL} / 4-18$, YSR, and TRF profiles. Burlington, VT: University of Vermont, Department of Psychiatry 1991.

[14] Heflinger CA, Simpkins CG, Combs-Orme T. Using the CBCL to determine the clinical status of children in state custody. Child Youth Serv Rev 2000; 22(1): 55-73.

[http://dx.doi.org/10.1016/S0190-7409(99)00073-0]

[15] Azar ST, Wolfe DA. Child physical abuse and neglect. Treatment of childhood disorders. Guilford 1998; pp. 501-44.

[16] Crittenden PM, Ainsworth M. Child maltreatment and attachment theory.Handbook of child maltreatment. Cambridge University Press 1989; pp. 432-63.

[http://dx.doi.org/10.1017/CBO9780511665707.015]

[17] Eckenrode J, Laird M, Doris J. School performance and disciplinary problems among abused and neglected children. Dev Psychol 1993; 29(1): 53-62.

[http://dx.doi.org/10.1037/0012-1649.29.1.53]

[18] Kolko DJ. Child physical abuse. 2002.

[19] Pardeck JT. Multiple placement of children in foster family care: An empirical analysis. Soc Work 1984; 29(6): 506-9. [http://dx.doi.org/10.1093/sw/29.6.506]

[20] Palmer SE. Placement stability and inclusive practice in foster care: An empirical study. Child Youth Serv Rev 1996; 18(7): 589-601. [http://dx.doi.org/10.1016/0190-7409(96)00025-4]

[21] Newton RR, Litrownik AJ, Landsverk JA. Children and youth in foster care: Distangling the relationship between problem behaviors and number of placements. Child Abuse Negl 2000; 24(10): 1363-74. [http://dx.doi.org/10.1016/S0145-2134(00)00189-7] [PMID: 11075702]

[22] Dorsey S, Farmer EM, Barth RP, Greene K, Reid J, Landsverk J. Current status and evidence base of training for foster and treatment 
foster parents. Child Youth Serv Rev 2008; 30(12): 1403-16. [http://dx.doi.org/10.1016/j.childyouth.2008.04.008]

[PMID: 21647272]

[23] Festinger T, Baker A. The quality of evaluations of foster parent training: An empirical review. Child Youth Serv Rev 2013; 35(12): 2147-53.

[http://dx.doi.org/10.1016/j.childyouth.2013.10.009]

[24] Christenson B, McMurtry J. A comparative evaluation of preservice training of kinship and nonkinship foster/adoptive families. Child Welfare 2007; 86(2): 125-40.

[PMID: 17533776]

[25] Christenson BL, McMurtry J. A longitudinal evaluation of the preservice training and retention of kinship and nonkinship foster/adoptive families one and a half years after training. Child Welfare 2009; 88(4): 5-22. [PMID: 20405775]

[26] Lee JH, Holland TP. Evaluating the effectiveness of foster parent training. Res Soc Work Pract 1991; 1: 162-74. [http://dx.doi.org/10.1177/104973159100100204]

[27] Puddy RW, Jackson Y. The development of parenting skills in foster parent training. Child Youth Serv Rev 2003; 12: 987-1013. [http://dx.doi.org/10.1016/S0190-7409(03)00106-3]

[28] Hambrick EP, Oppenheim-Weller S, N'zi AM, Taussig HN. Mental health interventions for children in foster care: A systematic review. Child Youth Serv Rev 2016; 70: 65-77.

[http://dx.doi.org/10.1016/j.childyouth.2016.09.002] [PMID: 28496286]

[29] Schoemaker NK, Wentholt W, Goemans A, Vermeer HJ, Juffer F, Alink L. A meta-analytic review of parenting interventions in foster care and adoption. Dev Psychopathol 2019; 1-24. [http://dx.doi.org/10.1017/S0954579419000798]

[30] Solomon DT, Niec LN, Schoonover CE. The impact of foster parent training on parenting skills and child disruptive behavior: A metaanalysis. Child Maltreat 2017; 22(1): 3-13.

[http://dx.doi.org/10.1177/1077559516679514] [PMID: 27909237]

[31] Uretsky MC, Hoffman JA. Evidence for group-based foster parent training programs in reducing externalizing child behaviors: A systematic review and meta-analysis. J Public Child Welf 2017; 11(4-5): 464-86. [https://doi.org/10.1080/15548732.2017.1326360]. [http://dx.doi.org/10.1080/15548732.2017.1326360]

[32] Van Andel H, Grietens H, Strijker J, Van der Gaag RJ, Knorth EJ. Searching for effective interventions for foster children under stress: A meta-analysis. Child Fam Soc Work 2014; 19(2): 149-55.

[http://dx.doi.org/10.1111/j.1365-2206.2012.00885.x]

[33] McNeil CB, Hembree-Kigin TL. Parent-child interaction therapy. New York, NY: Springer Science \& Business Media 2010.

[http://dx.doi.org/10.1007/978-0-387-88639-8]

[34] Eyberg SM, Robinson EA. Parent-child interaction training: Effects on family functioning. J Clin Child Psychol 1982; 11(2): 130-7.

[35] Carpenter AL, Puliafico AC, Kurtz SM, Pincus DB, Comer JS. Extending parent-child interaction therapy for early childhood internalizing problems: New advances for an overlooked population. Clin Child Fam Psychol Rev 2014; 17(4): 340-56. [http://dx.doi.org/10.1007/s10567-014-0172-4] [PMID: 25212716]

[36] Luby J, Lenze S, Tillman R. A novel early intervention for preschool depression: findings from a pilot randomized controlled trial. J Child Psychol Psychiatry 2012; 53(3): 313-22.

[http://dx.doi.org/10.1111/j.1469-7610.2011.02483.x] [PMID: 22040016]

[37] Chronis-Tuscano A, Lewis-Morrarty E, Woods KE, O'Brien KA, Mazursky-Horowitz H, Thomas SR. Parent-child interaction therapy with emotion coaching for preschoolers with attentiondeficit/hyperactivity disorder. Behav Cogn Psychother 2016; 23(1): 62-78. [https://doi.org/10.1016/j.cbpra.2014.11.00].

[38] McNeil CB, Quetsch LB, Anderson CM, Eds. Handbook of ParentChild Interaction Therapy for children on the autism spectrum. New York, NY: Springer 2019

[39] Chaffin M, Silovsky JF, Funderburk B, et al. Parent-child interaction therapy with physically abusive parents: efficacy for reducing future abuse reports. J Consult Clin Psychol 2004; 72(3): 500-10. [http://dx.doi.org/10.1037/0022-006X.72.3.500] [PMID: 15279533]

[40] Eyberg SM, Funderburk B. Parent-child interaction therapy protocol. Gainesville, FL: PCIT International 2011.

[41] Eyberg SM, Pincus D. Eyberg child behavior inventory and suttereyberg student behavior inventory-revised: Professional manual. Odessa, FL: Psychological Assessment Resources 1999.

[42] Lieneman CC, Brabson LA, Highlander A, Wallace NM, McNeil CB.
Parent-Child Interaction Therapy: Current perspectives. Psychol Res Behav Manag 2017; 10: 239-56.

[http://dx.doi.org/10.2147/PRBM.S91200] [PMID: 28790873]

[43] Danko CM, Garbacz LL, Budd KS. Outcomes of parent-child interaction therapy in an urban community clinic: A comparison of treatment completers and dropouts. Child Youth Serv Rev 2015; 60: $42-51$

[http://dx.doi.org/10.1016/j.childyouth.2015.11.007]

[44] Lieneman CC, Quetsch LB, Theodorou LL, Newton KA, McNeil CB. Reconceptualizing attrition in Parent-Child Interaction Therapy: "dropouts" demonstrate impressive improvements. Psychol Res Behav Manag 2019; 12: 543-55.

[http://dx.doi.org/10.2147/PRBM.S207370] [PMID: 31413647]

[45] Cohen J, Ed. Statistical power analysis for the behavioral sciences. Hillsdale, NJ: Erlbaum 1988.

[46] Sawilowsky S. New effect size rules of thumb. J Mod Appl Stat Methods 2009; 8(2): 467-74.

[http://dx.doi.org/10.22237/jmasm/1257035100]

[47] Boggs SR, Eyberg SM, Edwards DL. Outcomes of parent-child interaction therapy: A comparison of treatment completers and study dropouts one to three years later. Child Fam Behav Ther 2004; 26(4): $1-22$.

[http://dx.doi.org/10.1300/J019v26n04_01]

[48] Eyberg S, Boggs S, Jaccard J. Does maintenance treatment matter? J Abnorm Child Psychol 2014; 42(3): 355-66.

[http://dx.doi.org/10.1007/s10802-013-9842-9] [PMID: 24413969]

[49] Hood KK, Eyberg SM. Outcomes of parent-child interaction therapy: Mothers' reports of maintenance three to six years after treatment. J Clin Child Adolesc Psychol 2003; 32(3): 419-29.

[http://dx.doi.org/10.1207/S15374424JCCP3203_10] [PMID: 12881030]

[50] Kaminski JW, Valle LA, Filene JH, Boyle CL. A meta-analytic review of components associated with parent training program effectiveness. J Abnorm Child Psychol 2008; 36(4): 567-89.

[http://dx.doi.org/10.1007/s10802-007-9201-9] [PMID: 18205039]

[51] Lieneman C, Williford D, Quetsch L, Thomas B, McNeil CB. Behavioral treatments.Disruptive, impulse-control, and conduct disorders: Features, assessment, pathways, and intervention. Elsevier 2018; pp. 211-37.

[http://dx.doi.org/10.1016/B978-0-12-811323-3.00009-2]

[52] Thomas R, Zimmer-Gembeck MJ. Behavioral outcomes of parentchild interaction therapy and triple p-positive parenting program: A review and meta-analysis. J Abnorm Child Psychol 2007; 35(3): 475-95.

[http://dx.doi.org/10.1007/s10802-007-9104-9] [PMID: 17333363]

[53] Lieneman C, Girard E, Quetsch L, McNeil CB. Emotion regulation and attrition in Parent-Child Interaction Therapy. J Child Fam Stud 2019.

[http://dx.doi.org/10.1007/s10826-019-01674-4]

[54] Lanier P, Kohl PL, Benz J, Swinger D, Moussette P, Drake B. Parentchild interaction therapy in a community setting: Examining outcomes, attrition, and treatment setting. Res Soc Work Pract 2011; 1(6): 689-98.

[http://dx.doi.org/10.1177/1049731511406551] [PMID: 24839378]

[55] Leung C, Tsang S, Heung K, Yiu I. Effectiveness of Parent-Child Interaction Therapy (PCIT) among Chinese families. Res Soc Work Pract 2009; 19(3): 304-13.

[http://dx.doi.org/10.1177/1049731508321713]

[56] Lyon AR, Budd KS. A community mental health implementation of Parent-Child Interaction Therapy (PCIT). J Child Fam Stud 2010; 19(5): 654-68.

[http://dx.doi.org/10.1007/s10826-010-9353-z] [PMID: 20877583]

[57] Lanier P, Kohl PL, Benz J, Swinger D, Drake B. Preventing maltreatment with a community-based implementation of parent-child interaction therapy. J Child Fam Stud 2014; 23(2): 449-60. [http://dx.doi.org/10.1007/s10826-012-9708-8] [PMID: 24443637]

[58] Capous DE, Wallace NM, McNeil DJ, Cargo TA. Parent-child interaction therapy across diverse cultural groups.Parent-child interactions and relationships: Perceptions, practices and developmental outcomes. Nova Science Publishers 2016; pp. 1-44.

[59] Capage LC, Bennett GM, McNeil CB. A comparison between African American and Caucasian children referred for treatment of disruptive behavior disorders. Child Fam Behav Ther 2001; 23(1): 1-14. [http://dx.doi.org/10.1300/J019v23n01_01]

[60] Fernandez MA, Butler AM, Eyberg SM. Treatment outcome for low socioeconomic status African American families in Parent-Child Interaction Therapy: A pilot study. Child Fam Behav Ther 2011; 
33(1): $32-48$

[http://dx.doi.org/10.1080/07317107.2011.545011]

[61] Borrego J Jr, Anhalt K, Terao SY, Vargas EC, Urquiza AJ. ParentChild Interaction Therapy with a Spanish-speaking family. Cognit Behav Pract 2006; 13: 121-33.

[http://dx.doi.org/10.1016/j.cbpra.2005.09.001]

[62] Matos M, Torres R, Santiago R, Jurado M, Rodríguez I. Adaptation of parent-child interaction therapy for Puerto Rican families: A preliminary study. Fam Process 2006; 45(2): 205-22. [http://dx.doi.org/10.1111/j.1545-5300.2006.00091.x]

[PMID: 16768019]

[63] McCabe KM, Yeh M, Garland AF, Lau AS, Chavez B. The GANA program: A tailoring approach to adapting Parent-Child Interaction Therapy for Mexican Americans. Educ Treat Child 2005; 28: 111-29.

[64] Bigfoot DS, Funderburk BW. Honoring children, making relatives: the cultural translation of parent-child interaction therapy for American Indian and Alaska Native families. J Psychoactive Drugs 2011; 43(4): 309-18.

[http://dx.doi.org/10.1080/02791072.2011.628924] [PMID: 22400462]

[65] Phillips J, Morgan S, Cawthorne K, Barnett B. Pilot evaluation of parent-child interaction therapy delivered in an Australian community early childhood clinic setting. Aust N Z J Psychiatry 2008; 42(8): 712-9.

[http://dx.doi.org/10.1080/00048670802206320] [PMID: 18622779]

[66] Bjørseth $\AA$, Wichstrøm L. Effectiveness of Parent-Child Interaction Therapy (PCIT) in the treatment of young children's behavior problems. A randomized controlled study. PLoS One 2016; 11(9)e 0159845

[http://dx.doi.org/10.1371/journal.pone.0159845] [PMID: 27622458]

[67] Leung C, Tsang S, Sin TS, Choi S. The efficacy of Parent-Child Interaction Therapy with Chinese families: Randomized controlled trial. Res Soc Work Pract 2015; 25(1): 117-28. [https://doi.org/10.1177/1049731513519827].

[http://dx.doi.org/10.1177/1049731513519827]

[68] Briegel W, Walter T, Schimek M, Knapp D, Bussing R. Parent-Child Interaction Therapy: In-room-coaching. Ergebnisse einer ersten deutschen Fallstudie. Kindh Entwickl 2015; 24(1): 47-54. [http://dx.doi.org/10.1026/0942-5403/a000158]

[69] Hatamzadeh A, Pouretemad H, Hassanabadi H. The effectiveness of parent-child interaction therapy for children with high functioning autism. Procedia Soc Behav Sci 2010; 5: 994-7.

[http://dx.doi.org/10.1016/j.sbspro.2010.07.224]

[70] Hosogane N, Kodaira M, Kihara N, Saito K, Kamo T. Parent-Child Interaction Therapy (PCIT) for young children with Attention-Deficit Hyperactivity Disorder (ADHD) in Japan. Ann Gen Psychiatry 2018; 17(9)

[http://dx.doi.org/10.1186/s12991-018-0180-8]

[71] Park YN, Lee SY, Kim JY, Rhee ER. The effectiveness of parent-child interaction therapy for Korean families. Youngyuah Adong Jungsingungangyungu 2016; 9(1): 29-50.

[72] Chen YC, Fortson BL. Predictors of treatment attrition and treatment length in Parent-Child Interaction Therapy in Taiwanese families Child Youth Serv Rev 2015; 56: 28-37.

[http://dx.doi.org/10.1016/j.childyouth.2015.10.009] [PMID: 26705373]

[73] Abrahamse ME, Junger M, Chavannes EL, Coelman FJ, Boer F, Lindauer RJ. Parent-child interaction therapy for preschool children with disruptive behaviour problems in the Netherlands. Child Adolesc Psychiatry Ment Health 2012; 6(1): 24.

[http://dx.doi.org/10.1186/1753-2000-6-24] [PMID: 22694924]

[74] Eyberg SM, Boggs SR, Algina J. Parent-child interaction therapy: A psychosocial model for the treatment of young children with conduct problem behavior and their families. Psychopharmacol Bull 1995; 31(1): 83-91.

[PMID: 7675994]

[75] Timmer SG, Urquiza AJ, Herschell AD, et al. Parent-child interaction therapy: application of an empirically supported treatment to maltreated children in foster care. Child Welfare 2006; 85(6): 919-39. [PMID: 17305042]

[76] Timmer SG, Urquiza AJ, Zebell N. Challenging foster caregivermaltreated child relationships: The effectiveness of parent-child interaction therapy. Child Youth Serv Rev 2006; 28(1): 1-19. [http://dx.doi.org/10.1016/j.childyouth.2005.01.006]

[77] Eyberg S, Robinson EA. Dyadic Parent-Child Interaction Coding System: A manual. Psychological Documents 1983; 13 Ms. No. 2582.

[78] Fricker-Elhai AE, Ruggiero K, Smith DW. Parent-Child Interaction Therapy with two maltreated siblings in foster care. Clin Case Stud 2005; 4: 13-39.

[http://dx.doi.org/10.1177/1534650103259671]

[79] Goldfine ME, Wagner SM, Branstetter SA, McNeil CB. Parent-Child Interaction Therapy: An examination of cost-effectiveness. J Early Intensive Behav Interv 2008; 5(1): 119-41.

[http://dx.doi.org/10.1037/h0100414]

[80] Mersky JP, Topitzes J, Grant-Savela SD, Brondino MJ, McNeil CB Adapting Parent-Child Interaction Therapy to foster care: Outcomes from a randomized trial. Res Soc Work Pract 2016; 26(2): 157-67. [http://dx.doi.org/10.1177/1049731514543023]

[81] Werba BE, Eyberg SM, Boggs SR, Algina J. Predicting outcome in parent-child interaction therapy: success and attrition. Behav Modif 2006; 30(5): 618-46

[http://dx.doi.org/10.1177/0145445504272977] [PMID: 16894233]

[82] Timmer SG, Sedlar G, Urquiza AJ. Challenging children in kin versus nonkin foster care: perceived costs and benefits to caregivers. Child Maltreat 2004; 9(3): 251-62.

[http://dx.doi.org/10.1177/1077559504266998] [PMID: 15245678]

[83] Mersky JP, Topitzes J, Janczewski CE, McNeil CB. Enhancing foster parent training with parent-child interaction therapy: Evidence from a randomized field experiment. J Soc Social Work Res 2015; 6(4): 591-616.

[http://dx.doi.org/10.1086/684123] [PMID: 26977251]

[84] Timmer SG, Zebell NM, Culver MA, Urquiza AJ. Efficacy of adjunct in-home coaching to improve outcomes in parent-child interaction therapy. Res Soc Work Pract 2010; 20(1): 36-46.

[http://dx.doi.org/10.1177/1049731509332842]

[85] McNeil CB, Herschell AD, Gurwitch RH, Clemens-Mowrer L. Training foster parents in Parent-Child Interaction Therapy. Educ Treat Child 2005; 28: 182-96.

[86] Topitzes J, Mersky JP, McNeil CB. Implementation of parent-child interaction therapy within foster care: An attempt to translate an evidence-based program within a local child welfare agency. J Public Child Welf 2015; 9(1): 22-41.

[http://dx.doi.org/10.1080/15548732.2014.983288] [PMID: 25729340]

[87] Eyberg SM, Nelson MM, Duke M, Boggs SR, Eds. Manual for the dyadic parent-child interaction coding system. Thousand Oaks, CA: Sage Publications 2004.

[88] Abidin RR, Ed. Parenting Stress Index (PSI) manual. Odessa, FL: Psychological Assessment Resources 1995.

[89] Blair K, Bennett K, Mersky J, Topitzes J, McNeil CB. Brief PCIT: An intervention designed to reach more child welfare families. PCIT International Convention. Traverse City, Michigan. 2017.

[90] Blair K, Topitzes J, Winkler EN, McNeil CB. Parent-Child Interaction Therapy: Findings from an exploratory qualitative study with practitioners and foster parents. Qual Soc Work 2020:1473325020917722.

\section{(C) 2020 Han et al.}

This is an open access article distributed under the terms of the Creative Commons Attribution 4.0 International Public License (CC-BY 4.0), a copy of which is available at: https://creativecommons.org/licenses/by/4.0/legalcode. This license permits unrestricted use, distribution, and reproduction in any medium, provided the original author and source are credited. 